\title{
sciendo
}

\author{
Current Issues in Pharmacy and Medical Sciences \\ Formerly ANNALES UNIVERSITATIS MARIAE CURIE-SKLODOWSKA, SECTIO DDD, PHARMACIA \\ journal homepage: http://www.curipms.umlub.pl/
}

\section{Optimization of tablet formulation containing ginger dry extract}

\author{
Walid A.A. MaleK $^{1 *}{ }^{\circledR}$, Olena Anatolitvna Ruban ${ }^{1}{ }^{\circledR}$, \\ Olga V. Kutova ${ }^{2}$, Natalita A. Herbina ${ }^{1}{ }^{\circledR}$
}

\begin{abstract}
${ }^{1}$ Department of Industrial Technology of Drugs, National University of Pharmacy, Kharkov, Ukraine,
${ }^{2}$ Department of Processes and Equipment of Chemical and Pharmaceutical Production, National University of Pharmacy, Kharkov, Ukraine
\end{abstract}

\section{ARTICLE INFO}

Received 17 October 2019

Accepted 04 January 2020

\section{Keywords:}

diabetes mellitus,

tablets,

ginger dry extract,

design of experiment,

regression analysis,

vector optimization.

\begin{abstract}
Introduction. Diabetes mellitus is one of the world's most common diseases, therefore the development and introduction of new effective drugs for diabetes treatment into clinical practice is an important task for the health systems of many countries of the world.

Aim. The aim of our work was to determine and substantiate the quantitative ratio of excipients for the development of the optimal composition of directly compressible ginger dry extract tablets.

Materials and methods. To choose the optimal composition of tablets containing ginger dry extract, the effect of various quantitative ratios of the excipients Kollidon K30 and Neusilin UFL 2 on tablet mass pharmaceutical technical parameters, determined by established methods, was studied. For processing the experimental data, mathematical methods were used: design of experiment, regression analysis and a technique based on the theory of vector optimization.

Results. The interrelation between factors that were studied and technological parameters of tablet mass and compressed tablets were analyzed using regression equations.

Conclusions. The studies conducted allowed to chose the optimal composition of ginger dry extract tablets: ginger dry extract $-60 \%$, Galen IQ $721-34.5 \%$, Kollidon K30 - 3.5\%, Neusilin UFL $2-1 \%$, calcium stearate $-1 \%$. The chosen tablet formulation is characterized by pharmaceutical technical parameters meeting the requirements of the European Pharmacopoeia and the State Pharmacopoeia of Ukraine.
\end{abstract}

\section{INTRODUCTION}

Diabetes mellitus (DM) treatment is one of the important medical and social problems of our time and belongs to the priorities of national health systems in many countries of the world [1]. One of the widespread and effective methods of diabetes treatment is phytotherapy. Compared to drugs of chemical origin, herbal medicines are much more tolerable by the patients, have lower toxicity, do not cause severe side effects, but exert a mild nevertheless effective action $[2,3]$.

Ginger (Zingiber officinale) is a medicinal plant with a wide range of therapeutic properties due to its unique chemical composition. Pharmacological studies in laboratory

\footnotetext{
^ Corresponding author

e-mail: malekwalkhalaf@gmail.com
}

animals have shown that ginger extract possesses hypoglycemic and antioxidant activities, which indicates its promising potential for the development of new drugs for type 2 diabetes mellitus (T2DM) treatment $[3,4]$.

To develop a finished medicine that meets requirements of European Pharmacopoeia (Ph.Eur.), as well as the State Pharmacopoeia of Ukraine (SPhU), it is necessary to establish an optimal composition of a preparation, taking into consideration the effect of excipients on pharmaceutical technical properties which are important for obtaining solid dosage form of appropriate quality $[5,6]$.

In order to establish the tablet formulation, experimental design and regression analysis were used as powerful tools for experimental-statistical investigation and optimization in this study. The design of experiment (DoE) with factors at two levels $(-1 ;+1)$ carries the implication that 
the factor effect on the dependent variable is linear. When factors are evaluated only at the lower and upper levels, it is impossible to assess whether there is a nonlinear component in the ratio between the factors and the dependent variable. We suppose that the relationship between factors and the dependent variable is most likely non-linear. Therefore, additional experiments were conducted where factors were set at midpoints $(-1 ; 0 ;+1)$ to test linear and quadratic effects, as well as the interaction of factors. This approach is known for using non-compositional plans proposed by Box and Behnken. In this work, we used DoE - which is based on a combination of a two-level full factorial balanced incomplete block design with a balanced incomplete block design. The factorial experiment was supplemented with a minimum number of experiments at the central points. These are necessary to establish the second-order regression equation. This approach has allowed minimizing the experiment on the development of the formulation of the tablets, hence, save time and resources $[7,8]$.

The aim of this study was the determination of excipient quantitative composition for obtaining tablets with ginger dry extract by direct compression in order to achieve optimal pharmaceutical technical parameters of both the tablet mass and the tablets.

\section{MATERIALS AND METHODS}

The study object was ginger dry extract (manufactured by "Megaprom", Dnipro, Ukraine) and modern excipients for the production of tablets by direct compression: GalenIQ 721 (BENEO-Palatinit Gmb, Germany), Kollidon K30 (BASF, Germany), Neusilin UFL 2 (Fuji Chemical Industry, USA), calcium stearate (S.D. Fine Chemicals Ltd., India).

In preliminary studies devoted to the formulation development of directly compressed tablets containing $0.3 \mathrm{~g}$ of ginger dry extract with an average weight of $0.5 \mathrm{~g}$, the effect of three functional groups of excipients on pharmaceutical technical parameters was examined. According to the experimental results, Kollidon K30 was chosen as a binder, Neusilin UFL 2 - as a moisture regulator, and calcium stearate - as a lubricant. Based on available literature data, the amount of calcium stearate in the formulation was set to be $1 \%$ of the tablet average weight $[9,10]$.

To determine optimal amounts of Kollidon K30 and Neusilin UFL 2, various mathematical approaches such as design of experiment (DOE) and vector optimization theory have been used in this study $[11,12]$.

The results of planning the experiment according to the first-order $2^{2}$ factorial design on two levels are that a linear model is not realizable in this case. Due to this, we applied a more effective variant of planning - a symmetric non-composite second-order design according to the Box-Behnken model (Tables 1 and 2).
The study was performed as two independent duplicate series of 7 experiments in each one. All tablet formulations were prepared by blending ginger dry extract, tablet filler and lubricant with different amounts of Kollidon K30 ( $\left.\mathrm{X}_{1}\right)$ and Neusilin UFL $2\left(\mathrm{X}_{2}\right)$. The resulting tablet mass was thoroughly mixed and its pharmaceutical technical properties - bulk density, tapped density and Carr index - were determined and registered as response variables $\mathrm{y}_{1}, \mathrm{y}_{2}$ and $\mathrm{y}_{3}$, respectively $[5,6]$. The tablets were pressed in the laboratory single-punch tablet press (model HTM-01E, Mariupol plant of technological equipment, Ukraine) using flat cylindrical punches with the diameter of $11 \mathrm{~mm}$ and compression force of $100 \mathrm{Mpa}$.

Table 1. Factors and their levels for the experimental design

\begin{tabular}{|l|c|c|c|c|c|}
\hline \multirow{2}{*}{ Factors } & \multirow{2}{*}{ Unit } & \multirow{2}{*}{$\begin{array}{c}\text { Variation } \\
\text { interval }\end{array}$} & \multicolumn{3}{|c|}{ Levels } \\
\cline { 4 - 6 } & & & $\begin{array}{c}\text { Low } \\
\text { "-" }\end{array}$ & $\begin{array}{c}\text { Middle } \\
\text { "0" }\end{array}$ & $\begin{array}{c}\text { High } \\
\text { "+" }\end{array}$ \\
\hline $\mathrm{X}_{1}-$ Kollidon K30 & $\%$ & 1.5 & 2.0 & 3.5 & 5.0 \\
\hline $\mathrm{X}_{2}-$ Neusilin UFL 2 & $\%$ & 0.5 & 1.0 & 1.5 & 2.0 \\
\hline
\end{tabular}

Note. Tablet average weight was constant in all formulations and achieved by adding different proportions of tablet filler. Herein, Galen IQ 721 was selected on the basis of previous investigations [13]

Table 2. Tablet formulations which were tested according to Box-Behnken design

\begin{tabular}{|l|c|c|c|c|c|c|c|}
\hline \multirow{2}{*}{ Name of ingredient } & \multicolumn{7}{|c|}{ Amount, mg/per tablet } \\
\cline { 2 - 8 } & 1 & 2 & 3 & 4 & 5 & 6 & 7 \\
\hline Ginger dry extract & 300 & 300 & 300 & 300 & 300 & 300 & 300 \\
\hline Kollidon K30 & 25 & 25 & 10 & 10 & 17.5 & 17.5 & 17.5 \\
\hline Neusilin UFL 2 & 10 & 5 & 10 & 5 & 10 & 5 & 7.5 \\
\hline Galen IQ 721 & 160 & 165 & 175 & 180 & 167.5 & 172.5 & 170 \\
\hline Calcium stearate & 5 & 5 & 5 & 5 & 5 & 5 & 5 \\
\hline Mass of tablet (mg) & 500 & 500 & 500 & 500 & 500 & 500 & 500 \\
\hline
\end{tabular}

Tables obtained were subjected to the evaluation of their disintegration time, resistance to crushing and friability, which were response variables $\mathrm{y}_{4}, \mathrm{y}_{5}$ and $\mathrm{y}_{6}$, respectively $[5,6]$ (Table 3).

Table 3. Matrix of DOE and results of response variable determination

\begin{tabular}{|c|c|c|c|c|c|c|c|c|c|c|c|c|c|c|}
\hline 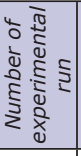 & $\mathrm{X}_{1}$ & $x_{2}$ & $y_{1}{ }^{\prime}$ & $\mathrm{y}_{1}{ }^{\prime \prime}$ & $y_{2}{ }^{\prime}$ & $y_{2}^{\prime \prime}$ & $\mathrm{y}_{3}{ }^{\prime}$ & $y_{3}{ }^{\prime \prime}$ & $y_{4}^{\prime}$ & $y_{4}^{\prime \prime}$ & $y_{5}{ }^{\prime}$ & $y_{5}{ }^{\prime \prime}$ & $y_{6}{ }^{\prime}$ & $y_{6}^{\prime \prime}$ \\
\hline 1 & + & + & 0.561 & 0.604 & 0.714 & 0.769 & 21.3 & 21.37 & 486 & 533 & 40.5 & 37.5 & 0.86 & 0.886 \\
\hline 2 & + & - & 0.580 & 0.599 & $\mid 0.714$ & 0.740 & 18.735 & 18.935 & 450 & 483 & 80.0 & 70.5 & 0.640 & 0.620 \\
\hline 3 & - & + & 0.548 & 0.568 & 0.714 & 0.740 & 23.23 & 23.18 & 434 & 449 & 59.75 & 60.5 & 0.836 & 0.730 \\
\hline 4 & - & - & 0.581 & 0.586 & 0.740 & 0.751 & 21.4 & 21.93 & 420 & 418 & 51.0 & 51.5 & 0.930 & 0.914 \\
\hline 5 & 0 & + & 0.591 & 0.606 & 0.769 & 0.8 & 23.1 & 24.14 & 484 & 464 & 77.0 & 81.0 & 0.758 & 0.714 \\
\hline 6 & 0 & - & 0.605 & 0.581 & 0.769 & 0.740 & 21.3 & 21.14 & 460 & 415 & 91.0 & 96.0 & 0.621 & 0.683 \\
\hline 7 & 0 & 0 & 0.625 & 0.606 & 0.769 & 0.769 & 18.75 & 21.19 & 475 & 438 & 118.5 & 119.0 & 0.528 & 0.528 \\
\hline
\end{tabular}

The performed regression analysis allowed presenting information obtained on the basis of experimental data in a compact form. The estimated empirical equations made it possible to determine the impact of factors $\left(\mathrm{X}_{1}, \mathrm{X}_{2}\right)$ on each pharmaceutical technical parameter with an acceptable error of not more than $3 \%$, using applicable mathematical software MathCad (Version 15). 
The approximation error $(\Delta)$, which determines the deviation from the maximum allowable error value, was calculated by the well-known formula:

$$
\Delta=\frac{\mathrm{y}_{\exp }-\mathrm{y}_{\text {theor }}}{\mathrm{y}_{\exp }} \times 100 \%
$$

The maximum and minimum values of the response variables within studied factor variation intervals were analyzed; factor value areas in which the parameters to be determine do not overstep the limits established by the researcher were also found.

\section{RESULTS AND DISCUSSION}

As a result of mathematical processing of the experimental data, we have obtained second-order empirical equations determining interrelation and degree of impact of the excipient amounts on the technological parameters of model tablet mixtures and tablets with dry ginger extract (Table 4).

Table 4. Regression equations for pharmaceutical technical parameters

\begin{tabular}{|l|l|}
\hline \multicolumn{1}{|c|}{ Response variables } & \multicolumn{1}{c|}{ Regression equations } \\
\hline $\mathrm{y}_{1}$ - bulk density & $\begin{array}{l}\mathrm{y}_{1}\left(\mathrm{x}_{1}, \mathrm{x}_{2}\right)=0.345+0.02 \mathrm{x}_{1}+0.318 \mathrm{x}_{2}+0.013 \mathrm{x}_{1} \mathrm{x}_{2}- \\
4.389 \mathrm{x}_{1}^{2}-0.129 \mathrm{x}_{2}\end{array}$ \\
\hline $\mathrm{y}_{2}$ - tapped density & $\begin{array}{l}\mathrm{y}_{2}\left(\mathrm{x}_{1}, \mathrm{x}_{2}\right)=0.634+0.089 \mathrm{x}_{1}-0.036 \mathrm{x}_{2}+0.11 \mathrm{x}_{1} \mathrm{x}_{2}- \\
0.015 \mathrm{x}_{1}^{2}+2 \times 10^{-3} \mathrm{x}_{2}^{2}\end{array}$ \\
\hline $\mathrm{y}_{3}$ - Carr index & $\begin{array}{l}\mathrm{y}_{3}\left(\mathrm{x}_{1}, \mathrm{x}_{2}\right)=37.026+2.346 \mathrm{x}_{1}-28.553 \mathrm{x}_{2}+ \\
0.32 \mathrm{x}_{1} \mathrm{x}_{2}-0.516 \mathrm{x}_{1}^{2}+9.86 \mathrm{x}_{2}^{2}\end{array}$ \\
\hline $\mathrm{y}_{4}$ - disintegration time & $\begin{array}{l}\mathrm{y}_{4}\left(\mathrm{x}_{1}, \mathrm{x}_{2}\right)=386.514-0.722 \mathrm{x}_{1}+16.083 \mathrm{x}_{2}+ \\
6.833 \mathrm{x}_{1} \mathrm{x}_{2}-1.389 \mathrm{x}_{1}^{2}-2 \mathrm{x}_{2}^{2}\end{array}$ \\
\hline $\mathrm{y}_{5}$ - crushing strength & $\begin{array}{l}\mathrm{y}_{5}\left(\mathrm{x}_{1}, \mathrm{x}_{2}\right)=-395.941+115.889 \mathrm{x}_{1}+428.687 \mathrm{x}_{2}- \\
15.042 \mathrm{x}_{1} \mathrm{x}_{2}-13.264 \mathrm{x}_{1}^{2}-130 \mathrm{x}_{2}^{2}\end{array}$ \\
\hline $\mathrm{y}_{6}$ - friability & $\begin{array}{l}\mathrm{y}_{6}\left(\mathrm{x}_{1}, \mathrm{x}_{2}\right)=3.298+-0.574 \mathrm{x}_{1}-2.347 \mathrm{x}_{2}+ \\
0.13 \mathrm{x}_{1} \mathrm{x}_{2}+0.05 \mathrm{x}_{1}^{2}+0.658 \mathrm{x}_{2}^{2}\end{array}$ \\
\hline
\end{tabular}

Analysis of the regression equation for bulk density showed that its maximum value of $0.618 \mathrm{~g} / \mathrm{ml}$ corresponds to the amounts of Kollidon K30 and Neusilin UFL 2 of 4.1\% and $1.4 \%$, respectively (Figure $1 \mathrm{a}$ ).

Maximum value of tapped density determined using the regression equation is $0.775 \mathrm{~g} / \mathrm{ml}$ under the amounts of Kollidon K30 and Neusilin UFL 2 of 3.7\% and 2.0\%, respectively (Figure 1b).

The analysis of the equation for the Carr index revealed passable flow properties of tablet mass for all value range of both factors $X_{1}$ and $X_{2}$ (i.e., the amounts of Kollidon K30 and Neusilin UFL 2, respectively) (Figure 1c). The minimum value of this parameter of 20.8 was provided by $5.0 \%$ and $1.8 \%$ of the mentioned excipients, respectively.

The regression equation describing the effect of disintegration time shows that the time that meets the requirements of Ph.Eur, and also SPhU, is achieved with all levels of factors. The minimum value of this parameter is $419 \mathrm{~s}$, which corresponds to the amounts of Kollidon K30 and Neusilin UFL 2 of $2.0 \%$ and $1.0 \%$, respectively (Figure 1d).

Analysis of the regression equation for the crushing strength of tablets demonstrated that when Kollidon K30 is contained in the amount of $3.5 \%$ and Neusilin UFL 2 - in the amount of $1.0 \%$, resistance to crushing is maximum and reaches the value of $93.2 \mathrm{~N}$ (Figure 1e).

The regression equation for friability determines the lowest value of tablet weight loss, which is $0.645 \%$, when $\mathrm{X}_{1}$ and $\mathrm{X}_{2}$ are $3.6 \%$ and $1.0 \%$, respectively, (Figure $1 \mathrm{f}$ ).

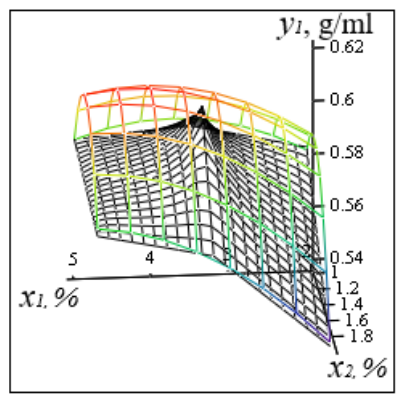

$a$

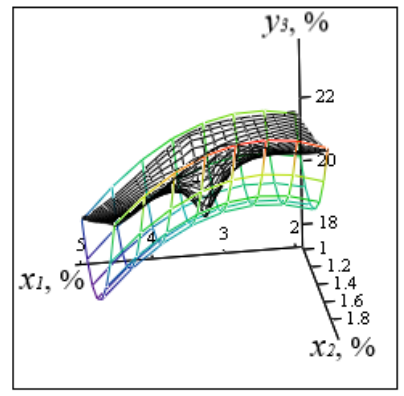

C

e

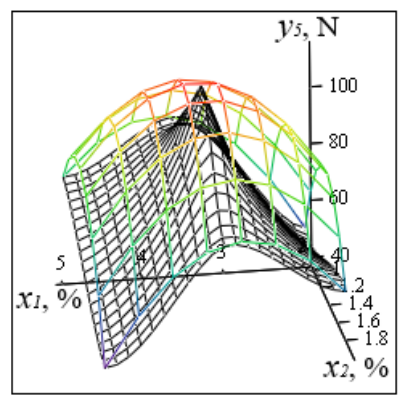

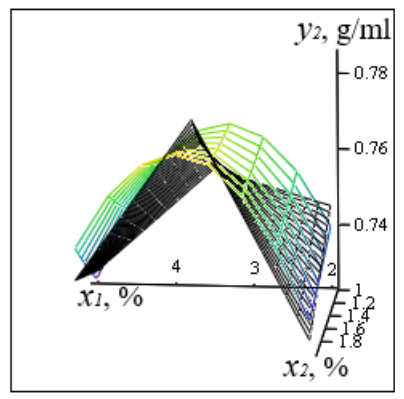

$b$
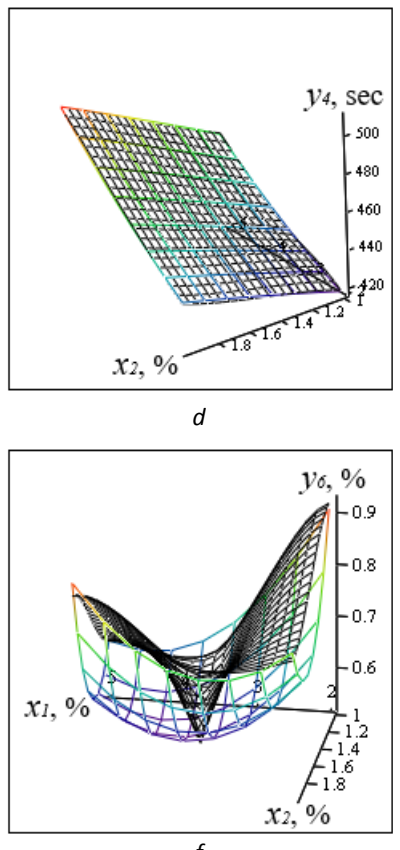

$f$
Figure 1. Comparison of experimental and theoretical dependencies according to the regression equations:

a) $y_{1}=f\left(x_{1}, x_{2}\right)$; b) $y_{2}=f\left(x_{1}, x_{2}\right)$; c) $\left.y_{3}=f\left(x_{1}, x_{2}\right) ; d\right) y_{4}=f\left(x_{1}, x_{2}\right)$; e) $y_{5}=f\left(x_{1}, x_{2}\right)$;f) $y_{6}=f\left(x_{1}, x_{2}\right)$

To determine the amounts of excipients that would equally provide optimal values of all pharmaceutical technical parameters, a technique based on the theory of multivector optimization was used. According to this technique, from the obtained range of acceptable solutions (Figure 2), those values of $X_{1}$ and $X_{2}$ are selected that equally satisfy all parameters simultaneously, taking into account the limitations applied by the researcher. In our case, the following conditions were determined:

- acceptable content ranges for Kollidon K30 and Neusilin UFL 2 are: $0.02 \leq \mathrm{X} 1 \leq 0.05 ; 0.01 \leq \mathrm{X} 2 \leq 0.02$, respectively;

- acceptable ranges of pharmaceutical technical parameters:

- bulk density: $0.55 \leq \mathrm{y} 1(\mathrm{X} 1, \mathrm{X} 2) \leq 0.62$;

- tapped density: $0.7 \leq \mathrm{y} 2(\mathrm{X} 1, \mathrm{X} 2) \leq 0.78$;

- Carr index: $20 \leq \mathrm{y} 3(\mathrm{X} 1, \mathrm{X} 2) \leq 23$;

- disintegration time: $418 \leq \mathrm{y} 4(\mathrm{X} 1, \mathrm{X} 2) \leq 530$;

- crushing strength: $41 \leq \mathrm{y} 5(\mathrm{X} 1, \mathrm{X} 2) \leq 93.33$;

- friability: $0.65 \leq \mathrm{y} 6(\mathrm{X} 1, \mathrm{X} 2) \leq 1.00$.

According to the method that is used to search for optimal parameters, the sum of squared deviation of each parameter value from its maximum, minimum or specified value, taking into account the limitations applied, should be minimal. Based on this condition, a function to search for 
optimal parameter values was formed and its minimum using the least squares method was found (Figure 2).

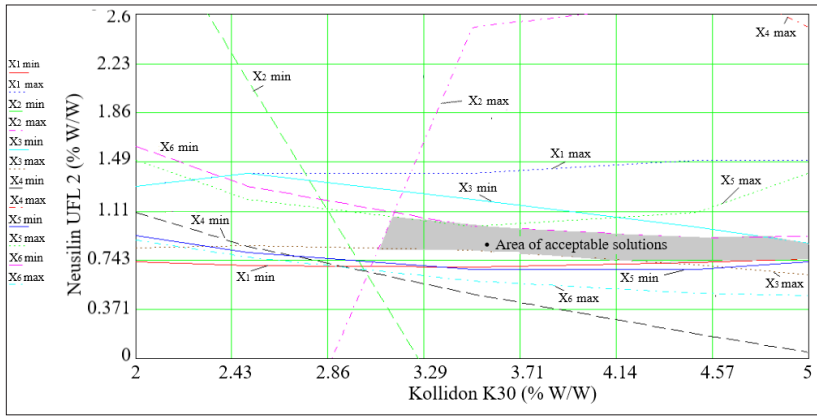

" - the optimal composition of ginger dry extract tablets with necessary pharmaceutical technical parameters)

Figure 2. Area of acceptable solutions

Thus, the optimal pharmaceutical technical parameters of the tablet mass and directly compressible tablets with ginger dry extract were obtained at $\mathrm{X}_{1}=3.5 \%$, and $\mathrm{X}_{2}=1.0 \%$.

Ginger dry extract tablets with specified excipient composition have pharmaceutical technical parameters that meet the requirements of Ph.Eur, as well as $\mathrm{SPhU}$, and are uniformly close to the given conditions: bulk density -0.595 $\mathrm{mg} / \mathrm{ml}$, tapped density $-0.765 \mathrm{mg} / \mathrm{ml}$, Carr index -21 , disintegration time $-439 \mathrm{~s}$, crushing strength $-93.3 \mathrm{~N}$ and friability $-0.65 \%$.

Thus, studies conducted allowed to chose the optimal composition of ginger dry extract tablets: ginger dry extract - 60\%, Galen IQ $721-34.5 \%$, Kollidon K30 - 3.5\%, Neusilin UFL $2-1 \%$, calcium stearate $-1 \%$.

\section{CONCLUSIONS}

1. By design of experiment and regression analysis methods, the quantitative effect of Kollidon K30 and Neusilin UFL 2 on pharmaceutical technical properties of the tablet mixture and tablets with ginger dry extract has been studied.

2. Using a technique based on the theory of multi-vector optimization, the optimal composition of ginger dry extract tablets with necessary pharmaceutical technical parameters meeting the requirements of $\mathrm{SPhU}$ was established as follows: Kollidon K30 - 3.5\%, Neusilin UFL 2 $-1.0 \%$.

\section{ORCID iDs}

Walid A.A. Malek (Dhttp://orcid.org/0000-0003-1188-0632 Olena Anatoliivna Ruban

(1Dhttps://orcid.org/0000-0002-2456-8210

Nataliia A. Herbina (1) https://orcid.org/0000-0001-9826-7552

\section{REFERENCES}

1. Zheng Y, Ley SH, Hu FB. Global aetiology and epidemiology of type 2 diabetes mellitus and its complications. Nat Rev Endocrinol. 2018;14:88-98.

2. Alkhalaf MV, Ruban OA, Gerbina NA, Masliy JuS. Studies of physico-chemical and pharmaco-technological properties of zingiber officinale dry extract. JPSR. 2018;10(1):5-7.

3. Kononenko NM, Chikitkina VV, Sorokina MV, Alkhalaf MW. Experimental rationale of selection of the hypoglicemic dose of ginger dry extract on normoglycemic rats. Pharml J. 2018;1-2:68-75.

4. Kononenko N, Sorokina M, Larianovska J, Chikitkina V. Impact of dry extract of ginger on morphological state of pancreas of syrian golden hamsters on the background of hypercalorium diet. Sciencerise: Pharm Sci. 2018;4:38-44.

5. State Pharmacopoeia of Ukraine: in 3 vol. State Enterprise «Ukrainian Scientific Pharmacopoeial Center for the Quality of Medicines». 2 ed. - Completed 1 - Kharkiv: State Enterprise, Ukrainian Scientific Pharmacopoeia Center for Quality of Medicinal Products; 2015:1128.

6. Council of Europe. European Pharmacopoeia, $9^{\text {th }}$ edition, Strasbourg: Council of Europe; 2016.

7. Garlapati VK, Lakshmishri R. Utilization of response surface methodology for modeling and optimization of tablet compression process. J Young Pharm. 2017;9(3):417-21.

8. Mehta DM, Dave DJ, Dadhaniya DV, Shelat PK, Parejiya PB, Barot BS. Application of box-behnken design to formulate and optimize multipolymeric fast dissolving film of rizatriptan benzoate. Asian J Pharm. 2014;8:38-45.

9. Alkhalaf Malek Walid Ahmad, Ruban OA, Kutova OV, Herbina NA. Substantiation of auxiliary substances of in the composition of tablets with dry extract of zingiber officinale. Biopharm J. 2019;3:23-28.

10. Rowe RC, Sheskey PJ, Cook WG, Fenton ME. Handbook of pharmaceutical excipients. Pharmaceutical Press and American Pharmacists Association; 2012:1033.

11. Groshovij TA, Marcenyuk VP, Kucherenko LI, Vrons ska LV, Gureiva SM. Mathematical planning of the experiment in conducting scientific research in pharmacy. Ternopil: Ternopil State Medical University; 2008:368.

12. Kutova OV, Kovalevskaya IV, Kutovy DS, Shapovalov AV, Zhuravsky AA. Certificate of registration of copyright to work 82707 Ukraine. Literary piece of writing scientific character Method of determining the optimal parameters of the process. date of registration 6.11.2018.

13. Ruban O, Alkhalaf M, Gerbina N. Selection of a filler for tablets manufactured with direct compression method containing dry ginger extract. EUREKA: Health Sciences. 2019;3:26-34. 